\title{
Expression of TP73L is a helpful diagnostic marker of primary mediastinal large B-cell lymphomas
}

\author{
Alberto Zamò ${ }^{1}$, Giorgio Malpeli ${ }^{1}$, Aldo Scarpa ${ }^{1}$, Claudio Doglioni ${ }^{2}$, Marco Chilosi ${ }^{1}$ \\ and Fabio Menestrina ${ }^{1}$ \\ ${ }^{1}$ Department of Pathology, University of Verona, Verona, Italy and ${ }^{2}$ Department of Histopathology, \\ San Raffaele Hospital, Milan, Italy
}

\begin{abstract}
Primary mediastinal large B-cell lymphoma is a well-defined lymphoma entity whose molecular pathogenesis is incompletely understood and also lacking well-established diagnostic markers. Recently, the presence of overlapping features between classical Hodgkin's lymphoma and primary mediastinal large B-cell lymphoma was highlighted by gene expression profiling as well as morphological studies. We investigated the expression of TP73L (commonly known as p63) isoforms in primary mediastinal large B-cell lymphoma at both protein and mRNA level, and demonstrated the exclusive presence of transactivating (TA) isoforms in all cases. We also demonstrated that TP73L is expressed in a subset of germinal center B-cells, as well as in some diffuse large B-cell lymphomas, but it is never present in classical Hodgkin lymphoma. Nodular lymphocyte predominant Hodgkin's lymphoma also showed TP73L positivity by immunohistochemistry. Isoform analysis by real-time PCR showed that TA-TP73L $\alpha$ is the most represented in primary mediastinal large B-cell lymphoma, but TA-TP73L $\gamma$ is the most differentially expressed in comparison to both germinal center B-cells and diffuse large B-cell lymphomas. TP73L expression proved a useful diagnostic marker of primary mediastinal large B-cell lymphoma, and gave new insights in to the molecular pathways playing a role in this lymphoma. Modern Pathology (2005) 18, 1448-1453. doi:10.1038/modpathol.3800440; published online 13 May 2005
\end{abstract}

Keywords: primary mediastinal large B-cell lymphoma; Hodgkin's lymphoma; TP73L; p63; real-time PCR; immunohistochemistry

Primary mediastinal large B-cell lymphoma is an aggressive non-Hodgkin's lymphoma subtype, ${ }^{1-6}$ recognized as a distinct entity in the WHO classifications of lymphoid ${ }^{7}$ and thymic $^{8}$ tumors. It affects mainly young adults, with a female predominance; the most common presentation is as a bulky mediastinal mass with frequent superior vena cava syndrome..$^{9,10}$ Primary mediastinal large B-cell lymphoma is considered a germinal-center or post germinal-center-derived lymphoma. ${ }^{1-13}$ Despite a good clinico-pathological definition, and the fact that multiple molecular and cytogenetic alterations have been described, ${ }^{14-21}$ the pathogenesis of primary mediastinal large B-cell lymphoma remains poorly understood. Recently, two groups defined a subset of gene transcripts that distinguish

Correspondence: Professor M Chilosi, MD, Dipartimento di Patologia, Sezione di Anatomia Patologica, Università di Verona, Strada Le Grazie, 8, 37134 Verona, Italy

E-mail: marco.chilosi@univr.it

Received 5 January 2005; revised 30 March 2005; accepted 1 April 2005; published online 13 May 2005 primary mediastinal large B-cell lymphoma from diffuse large B-cell lymphoma, ${ }^{22,23}$ thus concluding an endless discussion about the nosologic distinction between the two entities. These papers also highlighted unexpected similarities between primary mediastinal large B-cell lymphoma and Hodgkin's lymphoma; in accordance with these findings, some authors described the presence of 'gray-zone' lymphomas presenting features intermediate between primary mediastinal large B-cell lymphoma and mediastinal classical Hodgkin's lymphoma. ${ }^{24,25}$

TP73L (as defined by the HUGO nomenclature; also known as p63) is a member of the TP53 family, which also includes TP53 itself and TP73. ${ }^{26-28}$ Unlike TP53, the TP73L gene has two transcriptional starting sites (giving rise either to the transactivating (TA) or to the N-deleted $(\Delta \mathrm{N})$ variants) and its mRNA undergoes complex differential splicing, thus giving rise to at least six different molecular species with different biologic activities. ${ }^{29}$ At variance with TP53, mutations of $T P 73 L$ are rare in human cancer. ${ }^{30}$ To date, only two 
studies $^{31,32}$ have analyzed TP73L expression in a large variety of tumors including small series of lymphomas by immunohistochemistry and real-time RT-PCR. These studies showed TP73L nuclear positivity in a variable percentage of the different classes of non-Hodgkin's lymphomas, with the exception of mantle cell lymphoma and grade I follicular lymphoma. To our knowledge, the expression of TP73L has never been investigated in primary mediastinal large B-cell lymphoma. We analyzed TP73L isoforms in primary mediastinal large B-cell lymphoma by immunohistochemistry, as well as in Hodgkin's lymphoma, that constitute a major differential; ${ }^{25}$ for comparison, normal thymuses, reactive lymph nodes and other control tissues were stained; numerous cases of diffuse large B-cell lymphoma were also tested. To further confirm our immunohistochemical data and gain information about TP73L isoform prevalence, we performed an isoform-discriminating RT-PCR on samples of primary mediastinal large B-cell lymphoma, comparing results with both purified germinal center B-cells and diffuse large B-cell lymphoma cases.

\section{Materials and methods}

\section{Samples Selection}

Pathological samples were obtained from the archives of the Department of Pathology of the University of Verona, and included 13 cases of primary mediastinal large B-cell lymphoma, 34 cases of Hodgkin's lymphoma and 150 of diffuse large B-cell lymphoma. The 34 Hodgkin's lymphomas included six cases of nodular lymphocytepredominant Hodgkin's lymphoma and 28 of classical Hodgkin's lymphoma, four of which were localized to the mediastinum. Control tissues for immunohistochemistry included 10 reactive lymph nodes, 14 normal thymuses, three normal skin samples, four lungs, and two esophagi. Frozen tissue was available for eight primary mediastinal large B-cell lymphomas and 11 diffuse large B-cell lymphomas. Three normal donor tonsils were used for germinal center B cells isolation (described later).

\section{Immunohistochemistry}

Consecutive sections of primary mediastinal large B-cell lymphoma and controls were analyzed with three TP73L-specific antibodies: the first (clone 4A4, IgG2a-Santa Cruz Biotechnology, Santa Cruz, CA, USA) reacts with all known variants of human TP73L; the second ( $\mathrm{p} 40$, Oncogene Research Products, Boston, MA, USA) recognizes all $\triangle \mathrm{N}-\mathrm{TP} 73 \mathrm{~L}$ isoforms; the third (H-129 Santa Cruz Biotechnology) recognizes only $\alpha$ isoforms; $;^{33,34}$ this antibody was tested only in primary mediastinal large B-cell lymphomas and in five diffuse large B-cell lymphomas. Only nuclear staining was interpreted as positive. The antibody panel also included anticytokeratin 5 (clone XM26, Novocastra, Newcastle, UK), anti-cytokeratin 34 $\beta$ E12 (Dako, Glostrup, Denmark), anti-CD3 (clone PS1, Novocastra), antiCD1a (clone 010, Immunotech, Marseille, France), antiterminal deoxynucleotidyl transferase (Dako), anti-S100 protein (Dako), and anti-CD20 (clone L26, Dako). Technical details of the staining procedures have been previously described. ${ }^{33-35}$ Double staining was performed as previously described..$^{34}$ All samples were processed using a semiautomated staining system (GenoMx i6000, BioGenex, San Ramon, CA, USA).

\section{Germinal Center Cell Purification}

Germinal center B-cells were purified from three donor non-neoplastic tonsil tissue by negative magnetic-bead selection (MACS; Miltenyi Biotec GmbH, Cologne, Germany) as previously described. ${ }^{36}$ Sorted populations were over $96 \%$ purity as demonstrated by flow cytometric analysis using a FACScan cytofluorimeter (BD, San Jose, CA, USA).

\section{Quantitative RT-PCR}

Total RNA was extracted by cesium chloride gradient, ${ }^{37}$ and checked for integrity by gel electrophoresis. For each sample $1 \mu \mathrm{g}$ of RNA was reverse transcribed (First Strand cDNA Synthesis kit, Roche, Mannheim, Germany). Real-time quantification was performed by SYBR Green I detection chemistry with SYBR Green PCR Master Mix (PE Applied Biosystems, Warrington, UK) on a 7000 Sequence Detection System (PE Applied Biosystems). Each test gene assay included a cDNA template equivalent to $20 \mathrm{ng}$ of total RNA and a no-template control (in triplicate). As a control of quality and quantity of the RNA, ACTB ( $\beta$-actin), and GAPD (glyceraldehyde-3-phosphate dehydrogenase) were amplified in parallel with TP73L (data not shown). Primers and conditions were previously described. ${ }^{34}$

TP73L absolute expression was evaluated using a standard curve-based method. An absolute standard curve was plotted for each amplicon using serial dilutions of purified template DNA $(10,2,0.4,0.08,0.016 \mathrm{fg})$. Slopes of standard curves were -3.34 for TA-TP73L, -3.73 for TP73L $\alpha,-3.57$ for TP73L $\beta$, and -3.30 for TP73L $\gamma$; correlation coefficients were higher than 0.998. Data were plotted and statistically analyzed using SigmaPlot v8.0 software (SPSS, Chicago, IL, USA). The Student's $t$-test was used for comparison between data groups. 


\section{Results}

\section{Immunohistochemistry}

All cases of primary mediastinal large B-cell lymphoma showed nuclear reactivity with the 4A4 antibody (all TP73L isoforms) in $30-80 \%$ of the neoplastic cells (Figure 1, panel a), and with the H-129 antibody (specific for the $\alpha$ isoforms), whereas p40 nuclear immunostaining was absent. On the contrary, none of the 28 cases of classical Hodgkin's lymphoma was positive for TP73L (4A4 and p40 antibodies) (Figure 1, panel b), and, specifically, none of the four cases of mediastinal classical Hodgkin's lymphoma was positive. All nodular lymphocyte-predominant Hodgkin's lymphoma were positive in $10-40 \%$ of morphologically recognizable neoplastic cells, at variance with previous reports that showed a lower rate of reactivity in this lymphoma $^{31}$ (Figure 1, panel c). Residual normal thymic epithelial cells were 4A4 and p40 positive; the epithelial nature of these cells was confirmed by cytokeratin immunostaining on serial sections. Intrathymic B cells showed focal positivity for the 4A4 antibody, as shown by 4A4/CD20 double staining (Figure 1, panel d). In diffuse large B-cell lymphoma, TP73L (4A4) was expressed at various levels in 88 patients (59\%); most cases expressed the protein in $25-75 \%$ of cells. Sixty two patients $(41 \%)$ stained negative. All diffuse large B-cell lymphoma cases were negative when tested using the p40 antibody; H-129 was tested in a subset of five 4A4-positive cases, and was positive in all, despite a lower technical performance of the antibody.

\section{Real-Time PCR}

In accordance with immunohistochemical results, RT-PCR showed a complete absence of the $\Delta \mathrm{N}$ isoforms in primary mediastinal large B-cell lymphoma, germinal center B cells, and diffuse large
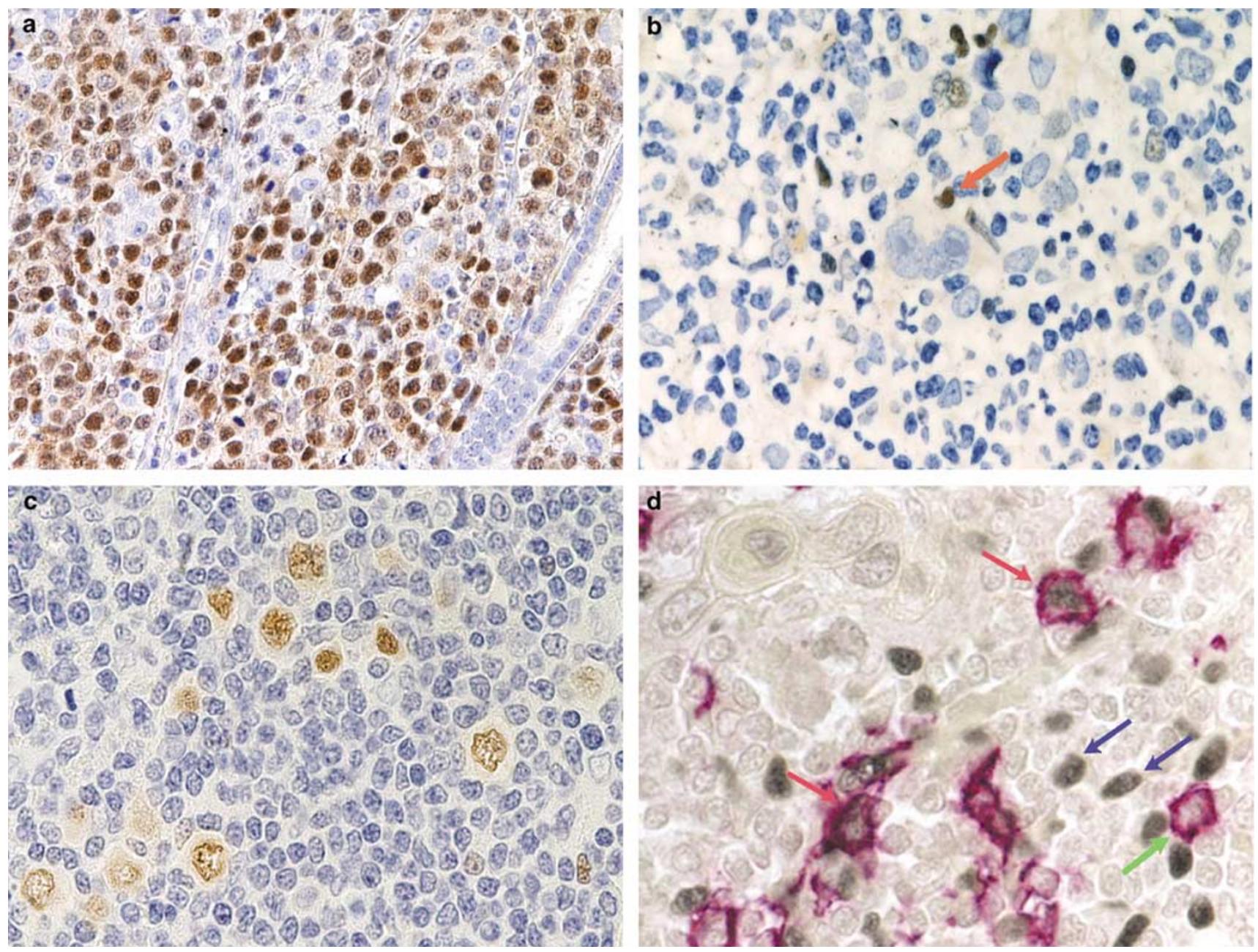

Figure 1 Immunohistochemistry for TP73L. (a) Primary mediastinal large B-cell lymphoma shows nuclear staining in most cells. (b) A Reed-Sternberg cell from a case of classical Hodgkin lymphoma stains negative; a few TP73L-positive small lymphocytes function as positive controls (red arrow). (c) L\&H cells from a case of nodular lymphocyte predominant Hodgkin lymphoma stain positively. (d) TP73L/CD20 double staining of normal thymus shows the presence of TP73L-positive B cells (red arrows), as well as some thymocytes (blue arrows); some B cells are TP73L-negative (green arrow). 
B-cell lymphoma (as positive controls we tested four thymoma samples-data not shown). All primary mediastinal large B-cell lymphoma showed TATP73L upregulation compared to both diffuse large B-cell lymphoma $(P=0.029)$, showing a mean $2.21-$ fold overexpression, and to GCBC $(P<0.001)$, with a mean 28.94-fold overexpression. Every TP73L isoform (ie $\alpha, \beta$ and $\gamma$ ) proved to be overexpressed in primary mediastinal large B-cell lymphoma when compared to both germinal center B cells and diffuse large B-cell lymphoma, with the exception of $\beta$, whose difference between primary mediastinal large B-cell lymphoma and diffuse large B-cell lymphoma was not statistically significant. The $\gamma$ isoform appeared to be the second most represented after $\alpha$, and the most upregulated, with a mean 115.21-fold overexpression in primary mediastinal large B-cell lymphoma compared to germinal center B cells and 5.16-fold to diffuse large B-cell lymphoma (Figure 2 ). The ratio between isoforms was different in the different groups. Namely, the $\alpha / \beta$ ratio was 68.34 for primary mediastinal large B-cell lymphoma, 16.81 for diffuse large B-cell lymphoma and 38.68 for germinal center B cells; the $\alpha / \gamma$ was 26.15 for primary mediastinal large B-cell lymphoma, 38.68 for diffuse large B-cell lymphoma and 77.26 for germinal center B cells; the $\beta / \gamma$ was 0.38 for primary mediastinal large B-cell lymphoma, 2.3 for diffuse large B-cell lymphoma and 1.99 for germinal center

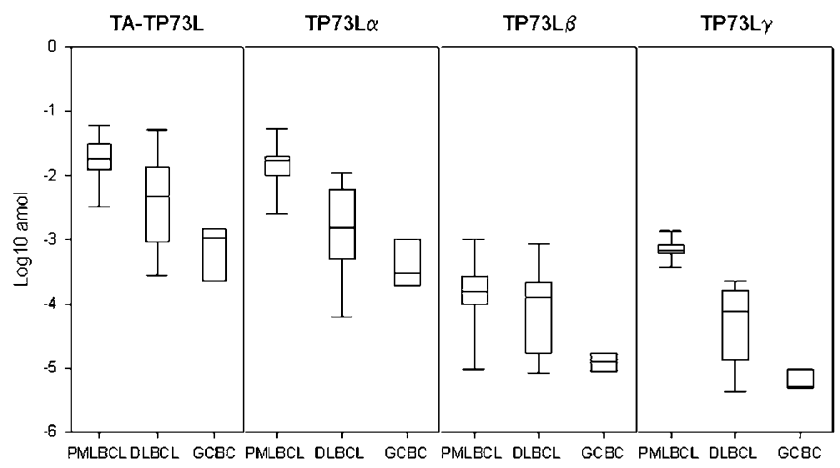

Figure 2 Boxplot representation of quantitative RT-PCR data. Primary mediastinal large B-cell lymphoma showed higher TP73L mRNA levels than diffuse large B-cell lymphoma and germinal center B cells for all species, except $\beta$ that is expressed at similar levels in primary mediastinal large B-cell lymphoma and diffuse large B-cell lymphoma.

Table 1 Ratios between TP73L isoforms

\begin{tabular}{lccc}
\hline & PMLBCL & DLBCL & $G C B C$ \\
\hline$\alpha / \beta$ & 68,34 & 16,81 & 36,68 \\
$\alpha / \gamma$ & 26,15 & 38,68 & 77,26 \\
$\beta / \gamma$ & 0,38 & 2,30 & 1,99 \\
\hline
\end{tabular}

PMLBCL: primary mediastinal large B-cell lymphoma; DLBCL: diffuse large B-cell lymphoma; GCBC: germinal center B cells.
B cells (Table 1). More detailed quantitative data are available from the authors upon request.

\section{Discussion}

We have studied primary mediastinal large B-cell lymphoma for the expression of TP73L, a multiedged protein belonging to the p53 family, whose $\Delta \mathrm{N}$ subtype is known to be involved in head and neck cancer. We analyzed TP73L expression at both protein and mRNA level, and showed that only the TA subgroup was present in primary mediastinal large B-cell lymphoma, in germinal center B cells and diffuse large B-cell lymphoma, and that primary mediastinal large B-cell lymphoma had the highest percentage of positive cases $(100 \%)$ by immunohistochemistry and the highest levels of TP73L RNA; on the contrary, no case of classical Hodgkin's lymphoma was positive at the protein level. We also showed that RNA levels and isoform expression are different in primary mediastinal large B-cell lymphoma, germinal center B cells and diffuse large B-cell lymphoma.

Two recent gene-expression profiling studies ${ }^{22,23}$ defined a subset of transcripts that distinguish primary mediastinal large B-cell lymphoma from diffuse large B-cell lymphoma, thus demonstrating that the two entities are nosologically distinct. The authors also found unexpected partial similarities in the expression profile between primary mediastinal large B-cell lymphoma and Hodgkin's lymphoma cell lines and microdissected Hodgkin-Reed-Sternberg cells. In accordance with these findings, some authors described the presence of so-called 'grayzone' lymphomas, showing features intermediate between classical nodular-sclerosis Hodgkin's lymphoma and primary mediastinal large B-cell lymphoma. ${ }^{24,25}$ Starting from this background, we demonstrated that TP73L really functioned as a watershed between the two related entities, because all primary mediastinal large B-cell lymphoma were TP73L-positive, while all classical Hodgkin's lymphoma were negative. Notably, in addition to primary mediastinal large B-cell lymphoma, TP73L appeared to be expressed in nearly all nodular lymphocyte-predominant Hodgkin's lymphoma, but not in classical Hodgkin's lymphoma.

The expression of TA-TP73L in primary mediastinal large B-cell lymphoma is consistent with its germinal center or post-germinal center molecular phenotype; in accordance, we showed that the mRNAs coding for the TA isoforms are the only ones present in normal germinal center cells, and by 4A4/CD20 double-staining non-neoplastic intrathymic B cells express TA-TP73L protein only. We could hypothesize that TA-TP73L is physiologically expressed in the normal cellular counterparts of primary mediastinal large B-cell lymphoma, and its expression is retained after lymphomatous transformation. Nevertheless, the total amount of TP73L is 
increased 28.94 times in primary mediastinal large B-cell lymphoma in comparison to germinal center B cells, and this suggests that TP73L gene transcription must be somehow upregulated.

Splice-variant expression in the TA subgroup showed that primary mediastinal large B-cell lymphoma overexpresses all the isoforms of TP73L RNA (only $\beta$ was expressed at levels similar to diffuse large B-cell lymphoma), and that the ratio between isoforms was different in primary mediastinal large B-cell lymphoma in comparison to the control groups. This is evidenced by the $\alpha / \beta$ ratio that was higher in primary mediastinal large B-cell lymphoma, especially if compared with diffuse large B-cell lymphoma, which appeared to be $\beta$-biased. On the other hand, the $\alpha / \gamma$ ratio was lower in primary mediastinal large B-cell lymphoma, indicating a relative increase in the $\gamma$ isoform that can activate TP53 molecular targets. ${ }^{29}$ The $\beta / \gamma$ ratio merits a mention in particular because germinal center $\mathrm{B}$ cells and diffuse large B-cell lymphoma had more $\beta$ than $\gamma$, while primary mediastinal large B-cell lymphoma showed an inverted ratio. Absolutely speaking, $\alpha$ was the most represented isoform, while the most upregulated one in primary mediastinal large B-cell lymphoma was $\gamma$, which was more than 8-fold overexpressed in comparison to diffuse large B-cell lymphoma, and more than 115-fold in comparison to germinal center B-cells; indeed, this isoform appeared as the most interesting candidate marker for primary mediastinal large B-cell lymphoma. However, since the biological function of TP73L isoforms is poorly understood, and their function in lymphoid cells is unknown, the pathogenetic significance of differential variant expression is purely speculative. A 'back-up' upregulation due to TP53 mutations is not probable, considering that only a minority of primary mediastinal large B-cell lymphoma bear a mutated TP53 gene. ${ }^{38}$

So far this has been the first study addressing TP73L expression in primary mediastinal large Bcell lymphoma and purified germinal center B-cells. We have shown that TP73L is detectable immunohistochemically in all cases of primary mediastinal large B-cell lymphoma, a feature that proved particularly useful in diagnostic practice, especially when mediastinal classical Hodgkin's lymphoma is considered as a differential diagnosis. The knowledge of TP73L variant usage in primary mediastinal large B-cell lymphoma and germinal center B cells provides the basis for further studies on the pathological and physiological role of this molecule.

\section{Acknowledgements}

This work was supported by AIRC (Associazione Italiana Ricerca sul Cancro, Milan, Italy). We thank Licia Montagna, Serena Pedron, Paola Piccoli and Claudia Parolini for their invaluable technical assistance.

\section{References}

1 Yousem SA, Weiss LM, Warnke RA. Primary mediastinal non-Hodgkin's lymphomas: a morphologic and immunologic study of 19 cases. Am J Clin Pathol 1985;83:676-680.

2 Addis BJ, Isaacson PG. Large cell lymphoma of the mediastinum: a B-cell tumour of probable thymic origin. Histopathology 1986;10:379-390.

3 Menestrina F, Chilosi M, Bonetti F, et al. Mediastinal large-cell lymphoma of B-type, with sclerosis: histopathological and immunohistochemical study of eight cases. Histopathology 1986;10:589-600.

4 Moller P, Lammler B, Eberlein-Gonska $\mathrm{M}$, et al. Primary mediastinal clear cell lymphoma of B-cell type. Virchows Arch A Pathol Anat Histopathol 1986; 409:79-92.

5 Moller P, Moldenhauer G, Momburg F, et al. Mediastinal lymphoma of clear cell type is a tumor corresponding to terminal steps of $\mathrm{B}$ cell differentiation. Blood 1987;69:1087-1095.

6 Momburg F, Herrmann B, Moldenhauer G, et al. B-cell lymphomas of high-grade malignancy frequently lack HLA-DR, -DP and -DQ antigens and associated invariant chain. Int J Cancer 1987;40:598-603.

7 Banks PM, Warnke RA. Mediastinal (thymic) large B-cell lymphoma. In: Jaffe ES, Harris NL, Stein H, Vardiman JV (eds). Pathology and Genetics of Tumours of Haematopoietic and Lymphoid Tissues. IARC Press: Lyon, 2001, pp 175-176.

8 Menestrina F, Harris NL, Moller P. Primary mediastinal large B-cell lymphoma. In: Travis WD, Brambilla E, Muller-Hermelink HK, Harris CC (eds). Pathology and Genetics of Tumours of the Lung, Pleura, Thymus and Hearth. IARC Press: Lyon, 2004, pp 222-224.

9 Cazals-Hatem D, Lepage E, Brice $\mathrm{P}$, et al. Primary mediastinal large B-cell lymphoma. A clinicopathologic study of 141 cases compared with 916 nonmediastinal large B-cell lymphomas, a GELA ('Groupe d'Etude des Lymphomes de l'Adulte') study. Am J Surg Pathol 1996;20:877-888.

10 Abou-Elella AA, Weisenburger DD, Vose JM, et al. Primary mediastinal large B-cell lymphoma: a clinicopathologic study of 43 patients from the Nebraska Lymphoma Study Group. J Clin Oncol 1999;17: 784-790.

11 Leithauser F, Bauerle M, Huynh MQ, et al. Isotypeswitched immunoglobulin genes with a high load of somatic hypermutation and lack of ongoing mutational activity are prevalent in mediastinal B-cell lymphoma. Blood 2001;98:2762-2770.

12 Malpeli G, Barbi S, Moore PS, et al. Primary mediastinal B-cell lymphoma: hypermutation of the BCL6 gene targets motifs different from those in diffuse large $\mathrm{B}$-cell and follicular lymphomas. Haematologica 2004; 89:1091-1099.

13 Csernus B, Timar B, Fulop Z, et al. Mutational analysis of IgVH and BCL-6 genes suggests thymic B-cells origin of mediastinal (thymic) B-cell lymphoma. Leuk Lymphoma 2004;45:2105-2110.

14 Copie-Bergman C, Boulland ML, Dehoulle C, et al. Interleukin 4-induced gene 1 is activated in primary mediastinal large B-cell lymphoma. Blood 2003;101: 2756-2761.

15 Copie-Bergman C, Gaulard P, Maouche-Chretien L, et al. The MAL gene is expressed in primary mediastinal large B-cell lymphoma. Blood 1999;94:3567-3575. 
16 Copie-Bergman C, Plonquet A, Alonso MA, et al. MAL expression in lymphoid cells: further evidence for MAL as a distinct molecular marker of primary mediastinal large B-cell lymphomas. Mod Pathol 2002;15:1172-1180.

17 Joos S, Otano-Joos MI, Ziegler S, et al. Primary mediastinal (thymic) B-cell lymphoma is characterized by gains of chromosomal material including 9p and amplification of the REL gene. Blood 1996;87:15711578.

18 Tsang P, Cesarman E, Chadburn A, et al. Molecular characterization of primary mediastinal B cell lymphoma. Am J Pathol 1996;148:2017-2025.

19 Scarpa A, Taruscio D, Scardoni M, et al. Nonrandom chromosomal imbalances in primary mediastinal Bcell lymphoma detected by arbitrarily primed PCR fingerprinting. Genes Chromosomes Cancer 1999;26: 203-209.

20 Bentz M, Barth TF, Bruderlein S, et al. Gain of chromosome arm $9 p$ is characteristic of primary mediastinal B-cell lymphoma (MBL): comprehensive molecular cytogenetic analysis and presentation of a novel MBL cell line. Genes Chromosomes Cancer 2001;30:393-401.

21 Palanisamy N, Abou-Elella AA, Chaganti SR, et al. Similar patterns of genomic alterations characterize primary mediastinal large-B-cell lymphoma and diffuse large-B-cell lymphoma. Genes Chromosomes Cancer 2002;33:114-122.

22 Rosenwald A, Wright G, Leroy K, et al. Molecular diagnosis of primary mediastinal B cell lymphoma identifies a clinically favorable subgroup of diffuse large B cell lymphoma related to Hodgkin lymphoma. J Exp Med 2003;198:851-862.

23 Savage KJ, Monti S, Kutok JL, et al. The molecular signature of mediastinal large B-cell lymphoma differs from that of other diffuse large B-cell lymphomas and shares features with classical Hodgkin lymphoma. Blood 2003;102:3871-3879.

24 Rudiger T, Jaffe ES, Delsol G, et al. Workshop report on Hodgkin's disease and related diseases ('grey zone' lymphoma). Ann Oncol 1998;9:S31-S38.

25 Calvo KR, Traverse-Glehen A, Pittaluga S, et al. Molecular profiling provides evidence of primary mediastinal large B-cell lymphoma as a distinct entity related to classic Hodgkin lymphoma: implications for mediastinal gray zone lymphomas as an intermediate form of B-cell lymphoma. Adv Anat Pathol 2004;11: 227-238.

26 Westfall MD, Pietenpol JA. p63: molecular complexity in development and cancer. Carcinogenesis 2004;25: 857-864.

27 Moll UM, Erster S, Zaika A. p53, p63 and p73-solos, alliances and feuds among family members. Biochim Biophys Acta 2001;1552:47-59.

28 Yang A, McKeon F. P63 and P73: P53 mimics, menaces and more. Nat Rev Mol Cell Biol 2000;1: 199-207.

29 Yang A, Kaghad M, Wang Y, et al. p63, a p53 homolog at 3q27-29, encodes multiple products with transactivating, death-inducing, and dominant-negative activities. Mol Cell 1998;2:305-316.

30 Osada M, Ohba M, Kawahara C, et al. Cloning and functional analysis of human p51, which structurally and functionally resembles p53. Nat Med 1998;4: 839-843.

31 Di Como CJ, Urist MJ, Babayan I, et al. p63 expression profiles in human normal and tumor tissues. Clin Cancer Res 2002;8:494-501.

32 Nylander K, Vojtesek B, Nenutil R, et al. Differential expression of p63 isoforms in normal tissues and neoplastic cells. J Pathol 2002;198:417-427.

33 Chilosi M, Poletti V, Murer B, et al. Abnormal reepithelialization and lung remodeling in idiopathic pulmonary fibrosis: the role of deltaN-p63. Lab Invest 2002;82:1335-1345.

34 Chilosi M, Zamo A, Brighenti A, et al. Constitutive expression of DeltaN-p63alpha isoform in human thymus and thymic epithelial tumours. Virchows Arch 2003;443:175-183.

35 Chilosi M, Poletti V, Zamo A, et al. Aberrant Wnt/betacatenin pathway activation in idiopathic pulmonary fibrosis. Am J Pathol 2003;162:1495-1502.

36 Morgan J, Reddy G, Uskokovic M, et al. Functional block for 1 alpha,25-dihydroxyvitamin D3-mediated gene regulation in human B lymphocytes. J Biol Chem 1994;269:13437-13443.

37 Glisin V, Crkvenjakov R, Byus C. Ribonucleic acid isolated by cesium chloride centrifugation. Biochemistry 1974;13:2633-2637.

38 Scarpa A, Moore PS, Rigaud G, et al. Molecular features of primary mediastinal B-cell lymphoma: involvement of p16INK4A, p53 and c-myc. Br J Haematol 1999;107:106-113. 